\title{
Brief Analysis on the Teaching Methods of Intermediate Macroeconomics of Economics and Management Majors
}

\author{
Yinping Chen ${ }^{1, a}$, Fenggang $\mathrm{Lu}^{2, \mathrm{~b}}$ \\ ${ }^{1}$ School of Economics, Harbin University of Commerce, Harbin, Heilongjiang Province, China \\ ${ }^{2}$ School of Economics, Harbin University of Commerce, Harbin, Heilongjiang Province, China \\ acyp0711@163.com, blfg0202@163.com
}

Keywords: Intermediate Macroeconomics; Teaching Methods; Multimedia Teaching

\begin{abstract}
In the first place, this paper analyses the differences among elementary economics, intermediate economics and advanced economics, and briefs courses design of macroeconomics popular in famous universities after then. Based on that, the paper brings forward patterns of intermediate macroeconomics lecture: double language teaching, integrating economic empirical pratices, multimedia teaching and so on, and so forth.
\end{abstract}

\section{Introduction}

Macroeconomics has been a spectacular discipline since the beginning of Keynes. Its theory is rich and complex, and its direct connection with economic practice is outstanding among many economic disciplines. Intermediate macroeconomics is the link between junior macroeconomics and senior macroeconomics. It builds a bridge to the palace of senior macroeconomics on the basis of junior macroeconomics.

Traditionally, western modern economics was called western economics in order to distinguish it from marxist political economy. There is no such thing as "western economics" abroad, especially in Europe and America.

Economics is not divided between east and west, but has branches and hierarchies. Economics is divided into microeconomics and macroeconomics. Based on this branch, there are elementary, intermediate and advanced economics in teaching practice.

As far as macroeconomics is concerned, the difference between advanced macroeconomics and elementary and intermediate macroeconomics is very obvious, and its basic feature is to show macroeconomic facts and laws by mathematical language and mathematical deduction process.

There is no strict boundary between primary and intermediate macroeconomics, which are similar or even identical in both content and presentation. In terms of differences, there are three specific points: (1) time limit tends to multi-period from single period, and cross-period model appears. (2) The research method changes from the emphasis on language, text and graph to the emphasis on mathematical theory. (3) In addition to the Keynesian macroeconomic theory, other school theories are also shown in depth.

\section{Establishment of Macroeconomics abroad}

In the foreign teaching practice, the first and second year students of the economics discipline set up elementary and intermediate macroeconomics, the senior students of the university set up advanced macroeconomics, the master and doctor continue to set up advanced macroeconomics courses, but the difficulty and level are improved gradually.

\section{Teaching methods of intermediate Macroeconomics}

\subsection{Using bilingual teaching method}

At present, China has conducted extensive exchanges with other countries in both academic and 
economic practices. Therefore, students' proficiency in English economic terms is extremely important. This requires the teacher to be able to skillfully use Chinese and English when teaching.

As a language, Chinese and English share a lot of similarities, but also have a lot of differences. With the existence of folk slang and idioms, the understanding of economics is not a direct translation between Chinese and English. For example, the English expressions of elementary, intermediate and advanced macroeconomics are Introduction To Macroeconomics、 Intermediate Macroeconomics、Advanced Economics; The empirical rule, as we usually call it, is called the Rules of Thumb. Many words mean omen, such as sign hint, signal, indication, predictor, warning, barometer, portent, augury, precursor, caveat, bode, presage, heads-up, pointer, divine, token, etc.

Compared with the teaching of elementary macroeconomics, the bilingual teaching of intermediate macroeconomics has many reasonable and advantageous aspects. After the study of primary economics, students have a basic understanding and cognition of economic terms, which provides a good foundation for bilingual teaching.

\subsection{Integrating economic practice into the classroom}

Macroeconomics and economic practice are closely linked, on the one hand, the principles and laws of macroeconomics can be directly used to guide economic practice. For example, in terms of total output, classical macroeconomics thought that total supply was a vertical curve (FIG. a), and Keynes thought that it was a curve sloping to the top right (in extreme cases, a parallel line) (FIG. c). This, combined with the aggregate demand curve skewed to the lower right, leads to different economic policies.

According to the classical economic theory, after the government expands the aggregate demand by increasing government expenditure, increasing public investment and other means, the aggregate demand curve moves to the upper right. As can be seen from FIG. a, it can only lead to price rise, but has no effect on actual output. This was the theoretical source of hoover's inaction in the 1929-1933 depression. On the contrary, in the extreme case of Keynes (FIG. c), government expansion of aggregate demand leads directly to an increase in aggregate output without any impact on prices. Naturally, the government could do more to turn the economy around by increasing public investment. This is the reason why the Roosevelt administration was able to save the capitalist world.

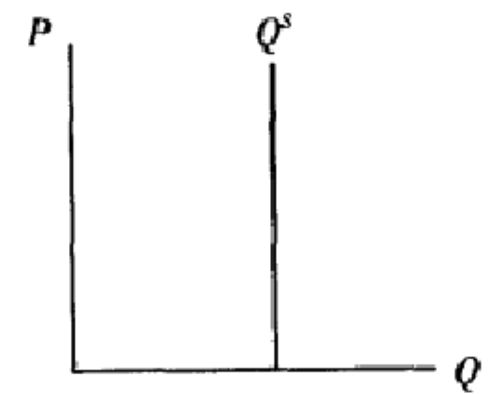

(a) Classical case

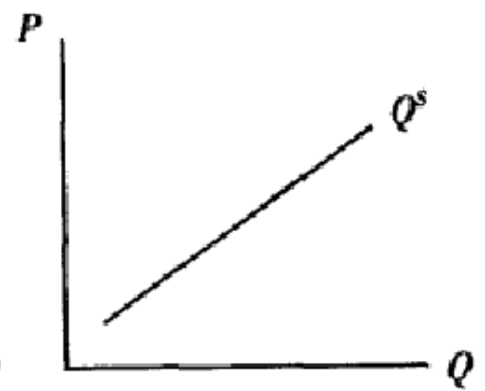

(b) Basic Keynesian case

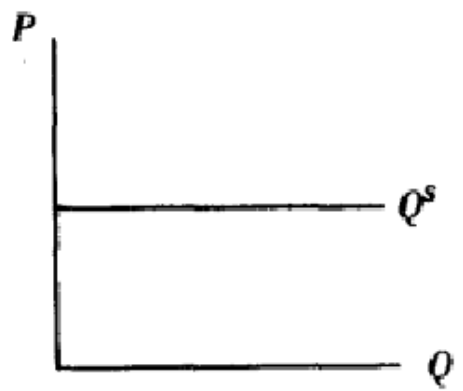

(c) Extreme case of Keynes

FIG.1 Aggregate Supply Curve

It is fair to say that Keynes saved the entire capitalist society on his own, although, Keynesian economics is widely reviled later.

On the other hand, macroeconomics is also a subject about realistic economic indicators. It is inevitable to mention GNP when talking about gross domestic product, but it is not found in various statistical databases. In China's national statistical yearbook, the gross national income is juxtaposed with the gross domestic product; in the world bank database, GNI is next to GDP. (FIG. 2) 


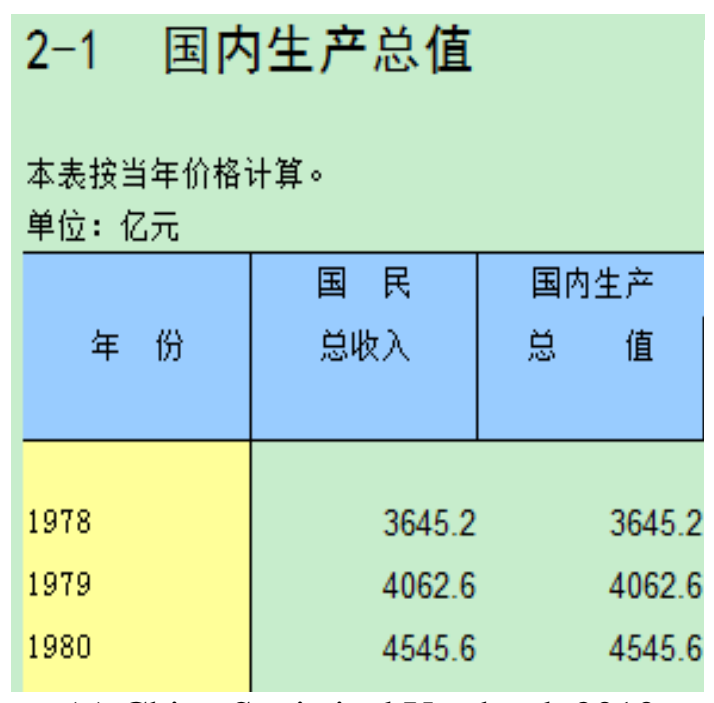

(a) China Statistical Yearbook 2010

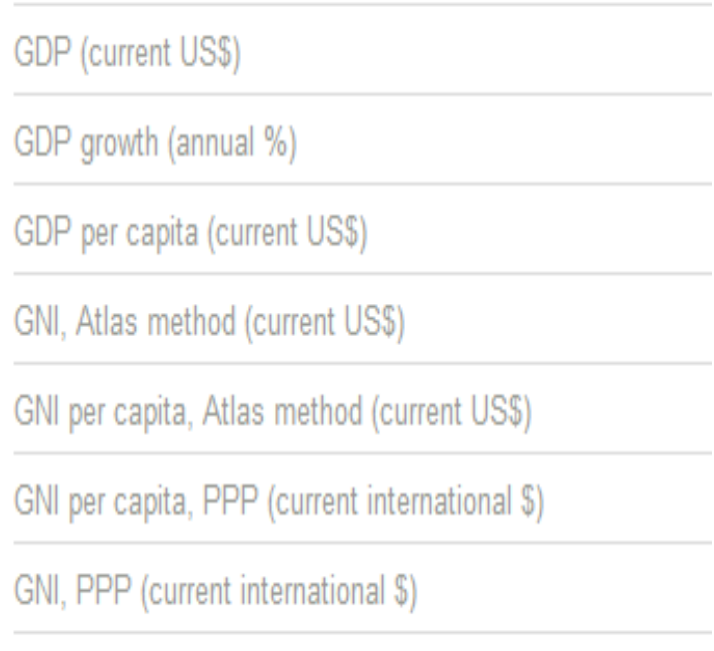

(b) Database of World bank

FIG.2 Gross National Income

In fact, gross national income is what was originally called gross national product. Since the 1990s, countries have gradually replaced gross national income with gross national product. In 1994, the United Nations, the world bank, the international monetary fund, the organization for economic cooperation and development and the commission of the European communities jointly promulgated the 1993 system of national accounts (1993SNA), in which the statistical term GNI replaced GNP; In 2001, GNP was completely replaced by GNI in the world bank database. In 2003, China adopted GNI.

In this way, integrating current economic indicators into the classroom in an intuitive way will be more conducive to students' understanding and mastery of macroeconomics.

\subsection{Using multimedia teaching method}

In response to the above two items, the teaching process should adopt the multimedia teaching method. Whether bilingual or combined with economic reality, the pure blackboard writing has been far from enough to meet the needs of modern economics teaching. It is not only intuitive, but also saves time for teachers and students. When teaching an economic indicator, the network address of the economic indicator can be directly linked to the field lecture in the class.

Multimedia teaching is not a pure use of PPT, the most essential symbol of multimedia teaching should be access to the Internet. In addition, although PPT teaching is intuitive and clear, the making process of PPT is a waste of time and energy. From the perspective of economics, the input and output of PPT teaching are too low.

In fact, as far as knowledge transfer is concerned, PDF file can completely replace PPT file. PDF files can be viewed in full screen, can be switched between reading mode and normal mode, and can adjust font display scale at will. Most importantly, the PDF file making process is extremely simple. Versions of Word above 2007 can be stored directly as a PDF file, while versions below 2007 can be converted through the installation of Acrobat related software, which takes just a few seconds to complete.

\subsection{Using exercises to consolidate knowledge}

At present, domestic colleges and universities mostly offer intermediate macroeconomics courses for senior students or postgraduates in economics. Problem sets and assignments seem to be designed specifically for undergraduates, graduate students to do research, not to do problem sets. This is actually a cognitive misconception. For graduate students, they only see "research" but not "birth", just like there is a big difference between ph. d. and ph. d. Candidate in English.

The study, reserve, production and innovation of knowledge are in stages, and can only be produced when it is time to learn. First to learn before production, first to "accept the reason" before "to spit new". Whether undergraduate, master or doctoral students are in the student stage, then 
learning is one of the main tasks. Only by laying a broad and profound foundation during the learning stage can we make great achievements in future scientific research and work.

Problem sets and assignments are the best way to consolidate knowledge. Homework can not only help students to review what they have learned, but also help them overcome their inertia.

As far as teaching practice is concerned, homework is not a problem, while correcting homework is a huge problem. At present, there are as many as one or two hundred students in large classes. If the teacher teaches several such classes in a semester, marking homework becomes an impossible task.

In the actual teaching process, the following methods can be adopted to promote students to complete homework and consolidate knowledge. First, set up a teaching assistant position, and the teaching assistant corrects the homework. This is a common practice in most universities. But there are drawbacks to this approach. Most teaching assistants are taken on by older students, and when there are too many assignments to grade, they are difficult to complete. On the one hand, this will affect the academic work of the teaching assistants, on the other hand, it will also lead to the teaching assistants to revise the assignments and do something perfunctorily, which will not achieve the purpose of actually helping the students. Second, adopt the method of receiving the assignments for grading. Each assignment takes a percentage of the work, which reduces the amount of work required to correct the assignment. Due to the uncertainty of the sampling, all students need to do their homework carefully, though not exactly. Third, include the usual assignments and problem sets in the final paper. This solves the problem of students' motivation mechanism for doing homework, and also avoids the occurrence of the phenomenon that some students simply copy their homework and hand in their work without paying any cost.

\section{References}

[1] Jeffrey Sachs.Macroeconomics from a Global Perspective (E.2ed) [M]. Shanghai Sanlian Press, 2003.

[2] N. Gregory Mankiw. Macroeconomics ((E.6th) [M]. China Renmin University Press, 2009.

[3] N.Grogory Mankiw. Macroeconomics (E.7th) [M].Worth Publishers.2010

[4] Paul R. Krugman. International Economics: theory and policy (E.6th) [M]. Addison Wesley, 2003. 